\title{
Satisfaction with dental care. A review of the literature.
}

Javiera Manríquez ${ }^{1}$ \& Karis Pereira ${ }^{1}$.

Abstract: The satisfaction of the patient is considered important to predict patient compliance, their ability to follow instructions, adherence to treatment and as a determining factor in the future use of health services. In Chile, there are currently not many studies or analyses in the health sector about the quality of care or level of satisfaction of patients. In most cases, these have only been studied through surveys, which are often initiated by the health services themselves, without using validated instruments. This article presents a review of the most relevant aspects described in the literature about satisfaction with dental care. The satisfaction that people experience in the use of a service or consumption of a product is a phenomenon that has been widely studied in recent decades. This concept has mainly been studied in two scientific areas: social psychology and an economistic approach. Multiple studies have demonstrated the multidimensional nature of user satisfaction in dentistry. Davies and Ware developed the Dental Satisfaction Questionnaire (DSQ) to assess access, availability, cost, pain management and quality. Several studies indicate that a positive relationship between the patient and the dentist generates higher satisfaction rates and that a negative relationship between the patient and the dentist leads to lower satisfaction rates on the part of the patients. As a result, a positive relationship with the dentist leads to greater commitment and interest in the dental treatment, generating greater adherence, better outcomes and increased satisfaction. Keywords: satisfaction, dental care, scales, health care.

\section{INTRODUCTION}

Improved quality of care has been a key objective in all health care systems worldwide, regardless of the cultural differences that exist. The satisfaction of the patient is considered important to predict patient compliance, their ability to follow instructions, adherence to treatment and as a determining factor in the future use of health services. This is why patient satisfaction is considered increasingly important in evaluation of the general quality of care and, therefore, in the improvement of health services (Mills et al., 2014).

Satisfaction in relation to medical care is a topic addressed in current methodologies for evaluating medical care programs. In this context, satisfaction can be considered an intermediate result of the medical care process which reflects the extent to which the care responds to the needs of patients, meets their expectations and provides an acceptable level of service (Stewart \& Spencer, 2002).

There are several instruments available to measure subjective variables about the quality of healthcare in health services. These instruments are made specifically according to the cultural conditions of the country in which they were made, studied and validated. It has been shown
INT J MED

Affiliations: ${ }^{1}$ Facultad de Odontología, Universidad Andrés Bello, Concepción,

Chile.

Corresponding author: Karis

Pereira. Dirección: Autopista Concepción - Talcahuano 7100, Concepción. Phone: +56979502411. E-mail: karis.pj@gmail.com.

$\begin{array}{ll}\text { Receipt: } & 04 / 12 / 2018 \\ \text { Revised: } & 04 / 18 / 2018 \\ \text { Acceptance: } & 05 / 25 / 2018 \\ \text { Online: } & 08 / 30 / 2018\end{array}$

Conflict of interests: None.

Ethics approval: Not required.

Funding: None.

Authors' contributions: All authors carried out the entire review.

Acknowledgements: None.

doi: $10.32457 /$ ijmss.2018.009. 
that the satisfaction of patients with dental care is affected by various factors and different measures have been used to evaluate it (Balkaran et al., 2014).

In Chile, currently in the health area, there have been some studies about the perception of quality of care or the level of satisfaction for the service provided to patients, in most cases being studied through surveys developed by health services themselves, without the use of validated instruments.

This article presents a review of the most relevant aspects described in the literature about satisfaction with dental care.

\section{CONCEPTS}

The satisfaction that people experience in the use of a service or the consumption of a product is a phenomenon that has been widely studied in recent decades. This concept has mainly been studied in two scientific areas; on the one hand, there are theories and models of social psychology, while on the other, an economistic approach has been used. In the area of economics and marketing, the measure of satisfaction is evaluated as a result or final state used to obtain a product or service, unlike psychoanalysts, who describe it more as a user evaluation process to determine who gets the product or service.

As stated earlier, psychology is one of the sciences that has most studied the concept of user and consumer satisfaction. There are multiple theories and models based on human behavior (Velandia et al., 2007).

The cognitivist position is based on previous experimental studies and proposes that satisfaction is considered as an evaluation that is a consequence of the process of relevant information. This process can be a comparison between the perceived performance of the service or product obtained and the standards that each person have (Vicente Martinez-Tur et al., 2014).

According to the affective position, satisfaction should not be understood as only concerning the processing of information, but should also consider the presence of the affective component as being fundamental. In this way, it is considered that at the moment of obtaining a service or product, the mental phenomena of the person related to subjective feelings, which are accompanied by emotions and moods, plays an important role (Vicente Martínez-Tur et al. al., 2014).

On the other hand, economists describe consumer satisfaction as a final result of the consumer experience. In this area, satisfaction is understood as the client's evaluation of a service that depends on how the service responded to their needs and expectations. If this is not fulfilled, dissatisfaction occurs (Mejías \& Manrique, 2011). Satisfaction is derived from an evaluation after obtaining a product or service and depending on the expectations prior to the said purchase. Customer satisfaction is defined as: "the level of a person's mood that results from comparing the perceived performance of a product or service with their expectations" (Kotler \& Armstrong, 2007).

To ensure optimum customer satisfaction, service providers must meet three very different criteria (Denove $\&$ Power, 2006): the objective quality of service, the subjective experience that the client has of the provision of the service, and the process of providing the service.

In accordance with the aforementioned factors, user satisfaction can be reflected in different phases and depend on various factors that influence the provision of a product or a service. It can be developed during or after consumption, and also involves the expectations and previous experiences of the user.

\section{SATISFACTION AND QUALITY IN MEDICAL CARE}

The perception of quality and satisfaction seem to be one of the most influential factors in evaluation of the healthcare sector. These concepts are intimately related since user satisfaction is one of the most important variables in health service quality assessments. However, these are not equal or equivalent terms. While judgments of quality of care are maintained over time and refer to specific characteristics in relation to the product or service, the expressions of satisfaction can change in different stages of care (Velandia et al., 2007). The quality of healthcare can be described objectively or subjectively, with the perception of the user being subjectively evaluated. In the absence of objective measures, users' perception should be used in order to measure and evaluate quality of service. 
Next is the concept of perceived quality of service, which is the subjective judgment of the user about the excellence or superiority of a product or service (Losada \& Rodriguez, 2007). The analysis of the quality of care has been carried out in the last few years under three dimensions proposed by Donabedian: the structure, the process and the result. The structure refers to the most established and invariant characteristics of how a health system is established and managed (amenities, physical facilities and organization), the process mainly refers to what professionals do (procedures and actions), and the results are the consequences of health care (changes in the state of health and the general perception of the care received) (Donabedian, 1986).

There are multiple studies that have attempted to relate this to the concept of satisfaction in different stages. There are three trends: the first is that satisfaction provokes a perception of quality, the second suggests that quality is the factor that influences satisfaction and the third theory suggests that the perceived quality of service would be both an antecedent and a consequence (Martínez -Tur et al., 2000).

Quality as a consequence of satisfaction is based on the fact that a general attitude is developed and modified over time from the experience of satisfaction with various services; that is, with the accumulation of specific evaluations (satisfaction of the service) a global or general evaluation is created (perceived quality).

Quality as a precedent for satisfaction argues that satisfaction is a more general concept that encompasses perceived quality, thus suggesting that improving the perceptions of service quality increases the levels of satisfaction.

Quality as an antecedent and consequence of satisfaction is an intermediate position, in which the satisfaction perceived after the attention received would be determined by the quality of the service which in turn will influence the long-term evaluation of the quality perceived by users.

The directionality of the relationship of the terms will be important in terms of what the service provider expects to have; i.e. whether their objective as a health center is to have more satisfied patients or if the perception of quality is more important.

\section{PATIENT SATISFACTION}

User satisfaction is a concept that encompasses multiple dimensions and has various definitions in the field of healthcare, based on social psychology and marketing. The evaluation of patient satisfaction as a measure of health care was largely addressed in the seventies and eighties by multiple authors. While the study in the seventies focused on determining those variables that influenced the satisfaction process, the consequences of its processing were also analyzed in the eighties (Kot/er \& Armstrong, 2007).

The first to refer to patient satisfaction term were Koos and Donabedian, for whom patient satisfaction is, above all, "a measure of the result of the interaction between health professionals and the patient" (Mejías $\&$ Manrique, 2011). Patient satisfaction is an objective and also a result focused on by the users of healthcare networks. From this perspective, it has progressively become a permanent concern of Health Services, both public and private (Donoso et al., 2009).

Patient satisfaction is considered an indicator of quality and can be defined as the degree of compliance by the health system with respect to user expectations regarding the services it offers (Donoso et al., 2009).

Other authors define it as a result of the difference between the perception that the person has of the service provided and of the expectations that he had at the outset or those that he may have in successive visits, in such a way that, if the expectations are greater than the perception of service, satisfaction will decrease. These expectations of the patient are forged from their own previous experiences and from the experiences reported by well-known people, as well as from the promises and commitments that the system itself acquires with the patients. Therefore, satisfaction cannot be considered a static dimension, since it can increase or decrease depending on the evolution of the two previously mentioned parameters (Davies \& Ware, 1982).

The WHO defined a number of dimensions for measuring patient satisfaction (Muza \& Muza, 2008). participation in decision-making related to health, access 
to information on the state of health, an empathic and human experience on the part of the professional, fast care and service provision, and appropriate infrastructure characteristics of the health service.

It is difficult to define a stable concept of satisfaction, which is why it is necessary to delve into the diverse factors that influence the answers of the respondents and which determine the degree of satisfaction. We can organize these factors in relation to the patient, the professional and the healthcare system.

In those related to the patient, we find the state of health with which the patient arrives (physical and fundamentally psychiatric pathologies of the patients), negative experiences, expectations, moods, and other personal factors such as age, gender, educational level, socioeconomic level, culture and language (Oliva \& Hidalgo, 2004; López et al., 2012; Nallar, 2014).

Regarding professional aspects, relevant factors are gender, specialty, staff attitude, knowledge and skills of health professionals (Oliva \& Hidalgo, 2004; Lopez et al., 2012; Nallar, 2014; López -Portilla et al., 2013).

Related to healthcare, the relationship established between the patient and the treating professional is important. The physician's empathy and level of communication are important determinants in the knowledge of the patient's needs and concerns, along with information regarding the diagnosis and treatment reported to the patient. This is also related to the place of care, cleanliness, privacy, comfort of the infrastructure, and the conditions of the instruments used. Finally, another variable in this area is accessibility, which is related to the time and manner of access to the health care center, along with economic access to the treatment plan (Oliva \& Hidalgo, 2004; López et al., 2012; Nallar, 2014; López-Portilla et al., 2013; Muza \& Muza, 2008).

\section{SATISFACTION WITH ATTENTION}

In the current literature, great importance has been placed on user satisfaction focused on medical and dental care and even on the perception of students and dentists towards the career itself. It must be remembered that patient satisfaction with dentists is crucial to enhance their ability to cooperate with treatment, follow recommendations and their commitment to attend the controls (Inglehart, 2016).

Several studies have been described in a number of countries which have evaluated healthcare, where user satisfaction is one of the main topics of study; for example, in Norway, dental satisfaction was assessed by means of the Dental Satisfaction Questionnaire (DSQ) (Skaret et al., 2004).

Other studies have focused on the perception of satisfaction of the dentist in the work area, specifically towards the public area (Janakiram et al., 2017). More studies in this field seek an evaluation of the level of user satisfaction with various dental treatments (Balushi et al., 2017; Lee et al., 2015), while others are focused on relating user satisfaction to oral health (Ayala-Luis et al., 2014) and further studies describe the factors that modify patient satisfaction (Adeniyi \& Adegbite, 2013).

Multiple studies have demonstrated the multidimensional nature of user satisfaction in dentistry. Davies and Ware carried out a prospective study to determine the most frequently used items for user evaluation in dentistry and determined that several of these were repeated constantly when reviewing the questionnaires of various studies, thus being able to develop the DSQ (Davies \& Ware, 1982; Skaret et al., 2004).

In the DSQ, 19 items assess various dimensions that are related to dental care. These dimensions are: access, availability, cost, pain management and quality. Good access provisions, clear advice and information are highly valued by patients, which is why it is necessary to improve them. Many patients reported problems contacting the dentist when the clinic or health service was closed, and difficulties in making requests over the phone (Anderson et al., 2005; Al-Neyadi et al., 2018). Another relevant aspect is the time spent waiting to enter the dental office or the waiting time to make requests; this is one of the items with the highest negative satisfaction index and one of the points that most significantly alters and modifies the answers when conducting surveys.

Availability can be influenced by the lack of dental appointments, lack of professionals, lack of dental 
office or the difficulty in obtaining dental appointments quickly (Skaret et al., 2004). It is important to remember that the time elapsed for the completion of a treatment will affect user satisfaction and is influenced by the availability of dental appointments or the efficiency with which the patient can obtain an appointment (López et al., 2013). The availability of services also depends on the country being evaluated; in Scandinavia, patients up to 18 to 21 years old belong to the public dental health system, whereas they enter the private system or require insurance after reaching the indicated age (Skaret et al., 2004).

In several studies, it has been observed that the item with the lowest valuation corresponds to the cost of services, where people feel that their value is much higher than the treatment performed. Stewart and Spencer (2002) described the lowest user satisfaction rates being found for cost, where the associated costs were reported and there was a feeling of little economic protection against dental expenses. Lower satisfaction rates were observed with respect to the ability to pay the values of dental care in young patients and in those who do not have dental insurance.

Most patients attend dental services because of pain, while only a small number of patients attend the dentist regularly for check-ups or assessments. For this reason, pain management is an important item when evaluating user satisfaction. It is important to evaluate pain management, not only because of the presence of pain and its management in emergencies, but also because of the generation of pain at the time of performing various dental treatments. It has been observed that the presence of pain when attending dental clinics from an early age is one of the causes of young adults resisting dental care in Norway (Skaret et al., 2004). This may be one of the reasons why people sometimes wait for so long before requesting dental care (Bencosme \& Macri, 2016). Another relevant aspect in this matter is postoperative pain, which forces the patient to request dental care again, as described in the study by Lee et al. (2015).

Several studies have indicated that a positive relationship between the patient and the dentist generates higher satisfaction levels and that a negative relationship between the patient and the dentist leads to lower satisfaction levels on the behalf of the patients. Accordingly, a positive relationship with the dentist leads to greater commitment and interest in the current treatment, generating greater adherence to treatments, better outcomes and increased satisfaction (Ayala-Luis \& Johansson, 2014; Al- Neyadi et al., 2018).

Verbal and non-verbal communication are key to user satisfaction as they reduce patient anxiety and lead to them favoring treatment. The sensitivity of the dentist, their response to the pain of the patient and their ability to resolve pain are the most important points (Anderson et al., 2005).

\section{REFERENCES}

Adeniyi A, Adegbite K, Braimoh M, Ogunbanjo B. Factors affecting patient satisfaction at the Lagos State University Teaching Hospital Dental Clinic. Afr J Med Med Sci. 2013;42(1):25-31.

Al Balushi S, Mei L, Farella M. Patient's satisfaction with orthodontic care from an academic clinical service. New Zealand Dental Journal. 2017;113(4): 13-20.

Al-Neyadi H, Abdallah S, Malik M. Measuring patient's satisfaction of healthcare services in the UAE hospitals: Using SERVQUAL. Int J Healthc Manag. 2018;11(2):96-105

Anderson R, Thomas D, Phillips C. The effectiveness of outof-hours dental services: II. patient satisfaction. $\mathrm{Br}$ Dent J. 2005;198(3):151-6.

Ayala-Luis J, Johansson V, Axtelius B, Soderfeldt B, Sampogna F. A multivariable analysis of patient dental satisfaction and oral health-related quality-of-life. A cross-sectional study based on DVSS and OHIP-14. Acta Odontol Scand. 2014;72(3):187-193.

Balkaran R, Osoba T, Rafeek R. A Cross-sectional Study of Patiens' Satisfaction with Dental Care Facilities: A Survey of Adult Treatment at The University of the West Indies, School of Dentistry. West Indian Med J. 2014;63(5):490-8

Bencosme, J., Macri, D. Pain Management in Dentistry. The Dental Assistant. 2016;85(2):38-40.

Davies AR, Ware JE, Jr. Development of a dental satisfaction questionnaire for the health insurance experiment. Santa Monica, CA: The Rand Corporation; 1982.

Denove C, Power IV. Satisfaction: How every great company listens to the voice of the customer. $1^{\circ}$ ed. London: Portfolio; 2006

Donabedian A. Quality assurance in our health care system. Qual Assur Util Rev. 1986;1(1):6-12

Donoso N, Díaz M, Peralta J. Medición Nacional de Satisfacción Usuaria en la Red Pública de Salud de Chile. Departamento Social Y Trato AI Usuario Subsecretaria De Redes De Asistencia, Santiago, Ministerio de Salud, Gobierno de Chile, 2009. factors analysis. Ingeniería industrial. 2011;32(1):43-47. Inglehart MR, Lee AH, Koltuniak KG, Morton TA, Wheaton JM. Do Waiting Times in Dental Offices Affect Patient Satisfaction and Evaluations of Patient-Provider Relationships? A Quasiexperimental Study. J Dent Hyg. 2016;90(3):203-11.

Janakiram C, joseph J, Antony B. Career Satisfaction among Dental Public Health Specialists in India - A Cross-sectional 
Survey. J Clin Diagn Res. 2017;11(1):ZC97-ZC101

Kotler P, Armstrong G. (2007). Marketing: versión para Lationamérica. $11^{\circ}$ ed. México: Pearson Educación; 2007.

Lee CT, Zhang S, Leung YY, Li SK, Tsang CC, Chu C-H. Patients' satisfaction and prevalence of complications on surgical extraction of third molar. Patient preference and adherence. 2015;9:257-263.

Lopez A, Almerich J, Montiel J. Estudio de la satisfacción del paciente en odontología mediante cuestionarios de salud: Adaptación al español del cuestionario "Dental Satisfation Questionnaire". [tesis Doctoral]. Valencia: Universidad de Valencia; 2012.

López-Portilla JE, et al. Determinantes de la satisfacción de la atención odontológica en un grupo de pacientes atendidos en la Clínica del Adulto de la Facultad de Odontología de la Universidad de Antioquia. Rev. Gerenc. Polit. Salud. 2013;12(24):209-55.

Losada M, Rodríguez A. Health service quality: a literature review from a marketing perspective. Cuad Administr. 2007; 20(34); 237-258.

Mejías-Acosta A, Manrique-Chirkova S. Dimensiones de la satisfacción de clientes bancarios universitarios: una aproximación mediante el análisis de factores/Dimensions of customer satisfaction at universities banks: an approach using Mills I, Frost J, Cooper C, Moles D, Kay E. Patient-centred care in general dental practice - a systematic review of the literature. BMC Oral Health. 2014;14:64.

Muza R, Muza, P. (2008). Satisfacción del paciente con tres especialidades dentales. Rev Chil salud pública. 2008;12(1):127.

Nallar M. Nivel de Satisfacción Usuaria en Atención Odontológica en el CESFAM Rosita Renard de la comuna de Ñuñoa [tesis pregrado]. Santiago: Universidad Andrés Bello; 2016.

Oliva C, Hidalgo CG. Satisfacción Usuaria: Un Indicador de Calidad del Modelo de Salud Familiar, Evaluada en un Programa de Atención de Familias en Riesgo Biopsicosocial, en la Atención Primaria. Psykhe. 2004;13(2):173-86.

Skaret E, Berg E, Raadal M, Kvale G. Reliability and validity of the Dental Satisfaction Questionanaire in population of 23-years-old in Norway. Community Dent Oral Epidemiol. 2004;32(1):25-30.

Stewart FJ, Spencer JA. Dental satisfication survey, AlHW; 2002;141:36.

Vicente Martínez-Tur, José M. Peiró, José Ramos \& Núria Tordera. Contribuciones de la Psicología Social al estudio de la satisfacción de los usuarios y consumidores. Rev Psicol Soc. 2000;15:(2):117-136. 